$17^{\text {th }}$ International Congress of Metrology, 08002 (2015)

DOI: $10.1051 /$ metrology / 201508002

(C) Owned by the authors, published by EDP Sciences, 2015

\title{
Metrological traceability for moisture content analysis in wood pellets
}

\author{
Michela Sega ${ }^{1, a}$, Giulio Beltramino ${ }^{1}$, Vito Fernicola ${ }^{1}$, Francesca Rolle ${ }^{1}$ and Alberto Verdoja ${ }^{1}$ \\ ${ }^{1}$ INRiM-Istituto Nazionale di Ricerca Metrologica, Strada delle Cacce 91, 10135 Torino, Italy
}

\begin{abstract}
Résumé. Ce travail décrit les procédés métrologiquement valides mises en place au INRiM pour la détermination du contenu d'eau dans des échantillons de boulettes de bois, en utilisant deux méthodes électrochimiques, à savoir le titrage coulométrique Karl Fischer (cKF) et «Evolved Water Vapour» (EWV), et la thermogravimétrie (TG), qui est inclue parmi les techniques basées sur les pertes sur par séchage. Les résultats préliminaires obtenus sont présentés. Les paramètres de fonctionnement les plus importantes ont été examinés et une attention particulière a été consacrée à la mise en place de la traçabilité métrologique des résultats de mesure. Les différentes techniques donnent des résultats en bon accord dans les incertitudes. On a trové que la homogénéité des échantillons et la température de séchage sont les grandeurs d'influence les plus importantes dans l'ensemble du processus de détermination de l'humidité..
\end{abstract}

\section{Introduction}

Pellets are wood derivatives used as fuel in wood stoves. They are prepared from dried sawdust which is then compressed in cylinder-shaped pieces having diameter of some millimeters. Pellets are replacing the use of wood logs in wood stoves of latest generation, providing improvements in terms of environment sustainability and energy management. The content of moisture is a determining factor for many physical and chemical properties of such material and it has a considerable impact in determining the product calorific value [1].

The current state of the art of moisture measurement in solids relies on moisture analyses according to standardised procedures in most of which moisture is determined as the mass loss measured by weighing a sample before and after drying it in a suitable oven (Loss on Drying - LoD method). However, oven drying is not water selective but might extract also other volatiles and the sample may still contain residual water after drying $[2,3]$. In addition, a rigorous measurement uncertainty analysis is in many cases unavailable. For these reasons, there is a need of implementing measurement methods which can assure full metrological traceability to SI.

The Istituto Nazionale di Ricerca Metrologica (INRiM) is developing the metrology infrastructure for providing traceability to moisture in materials. Such efforts are carried out within the European Joint Research Project EMRP SIB64 METefnet - Metrology for Moisture in Materials [3] in cooperation with several other European National Metrology Institutes. The present work deals with the metrologically-sound procedures set up at INRiM for the determination of water content in samples of wood pellets, by using two electrochemical methods, namely coulometric Karl Fischer (cKF) titration and Evolved Water Vapour analysis (EWV), and the thermogravimetry (TG) which is included among the LoD techniques. The preliminary results obtained are presented.

\section{Experimental}

The first part of the work was devoted to the optimisation of operating parameters for the different techniques. Secondly, the establishment of metrological traceability for measurement results was addressed, by using suitable reference materials (Hydranal Water Standard ${ }^{\circledR}$ KF Oven $5.55 \%)$ to calibrate the electrochemical instruments and calibrated mass standards to carry out the mass determination of samples.

The different techniques were used in parallel to determine the content of moisture present in selected samples of pellet. The work was mainly focused on comparing $\mathrm{cKF}$ and EWV results, while thermogravimetry was used as a confirmation technique.

Some details on the different techniques are reported.

\subsection{Coulometric Karl Fischer titration}

\footnotetext{
${ }^{a}$ Corresponding author: m.sega@inrim.it
} 
The cKF titration is a chemical direct method that uses a reaction selective to water based on the oxidation of sulphur dioxide $\left(\mathrm{SO}_{2}\right)$ :

$$
3 \mathrm{Z}+\mathrm{ROH}+\mathrm{SO}_{2}+\mathrm{I}_{2}+\mathrm{H}_{2} \mathrm{O} \rightarrow 3 \mathrm{ZH}^{+}+\mathrm{ROSO}_{3}{ }^{-}+2 \mathrm{I}^{-}
$$

where $\mathrm{Z}$ is a base and $\mathrm{ROH}$ is an alcohol (usually methanol).

The consumption of iodine $\left(\mathrm{I}_{2}\right)$, which is stoichiometrically equivalent to the water present in the sample, is measured: $I_{2}$ is produced by the generating electrode from iodide $\left(\mathrm{I}^{-}\right)$and the end point is determined by a second electrode. The mass of water present in the sample is calculated from the amount of electric current (Coulomb) used for $\mathrm{I}_{2}$ production.

The apparatus used at INRiM is a Karl Fischer c30 (Mettler-Toledo) having a moisture measurement range between $2 \mathrm{ppm}$ and $5 \%$ of water. The system is equipped with a Stromboli oven. Solid samples are heated in the oven and the volatile compounds are brought into the KF titration cell for selective water determination. The following operational parameters were considered and optimized during the method development: duration of analysis, sample heating temperature, stirring rate, drift evaluation, ambient parameters (like relative humidity and temperature), repeatability, sample pre-treatment.

\subsection{Evolved Water Vapour analysis}

The Evolved Water Vapour (EWV) analysis was carried out at INRiM by using a commercial instrument Sartorius WDS 400 having a moisture measurement range between $1 \mathrm{ppm}$ and $40 \%$ of water and requiring a sample weight between 5 to $2000 \mathrm{mg}$. It is equipped with a phosphorous pentoxide $\left(\mathrm{P}_{2} \mathrm{O}_{5}\right)$ sensor and a coulometric detector. The instrument can differentiate among surface, capillary and crystallisation water. The solid samples are placed into a drying oven; a flux of dried air carries the water vapour on the sensor where $\mathrm{P}_{2} \mathrm{O}_{5}$ absorbs the water vapour by forming phosphoric acid. The reaction product is then electrolysed to yield hydrogen $\left(\mathrm{H}_{2}\right)$ and oxygen $\left(\mathrm{O}_{2}\right)$ and regenerating $\mathrm{P}_{2} \mathrm{O}_{5}$. The main operational parameters to be checked and optimised during the method development are the following: efficiency of the desiccant system, stability of the background during the analyses, sample position in the oven, sample heating temperature, repeatability, sample pre-treatment.

\subsection{Thermogravimetry}

Thermogravimetry (TG) is a technique based on continuous recording of mass changes of a sample of material, as a function of a combination of temperature with time until it reaches a constant value. The measurements at INRiM were carried out by a Thermobalance Sartorius MA150 on ground pellet samples of about $1 \mathrm{~g}$. As a proper calibration of the balance during the analysis is not possible, a verification of the balance performance was carried out at ambient temperature before and after each analytical run by using calibrated mass standards.

\section{Results and discussion}

Regardless the used technique, sample homogeneity and drying temperature were found to be the most important influence quantities in the entire moisture determination process.

\subsection{Sample pre-treatment}

The pre-treatment of the sample is a crucial step in the entire measurement process. The used techniques requires low amount of samples in order to comply with the moisture detection ranges, hence a single piece of pellet cannot be analysed directly. Two different ways of pre-treating the pellets were investigated, i.e. manual crushing and mechanical grinding. The main factors to be considered in evaluating the techniques resulted in the homogeneity of the sample and the minimisation of contamination from the environment. Figure 1 reports, as an example, a comparison between two typical sets of repeated measurements carried out by $\mathrm{cKF}$ at a temperature of $220{ }^{\circ} \mathrm{C}$ on two subsets of samples obtained with the two different techniques.

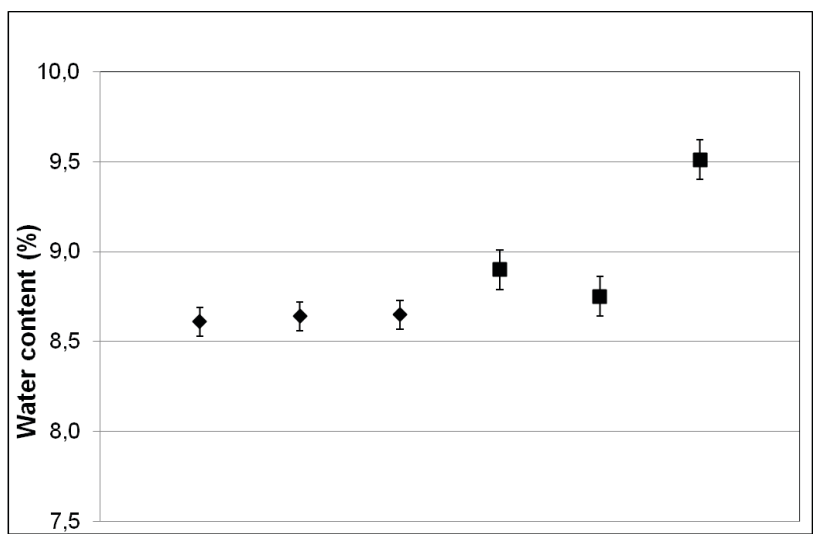

Figure 1. Comparison between sample pre-treatment techniques: mechanical grinding $(\diamond)$ and manual crushing (

The data presented in Figure 1 show that the mechanical grinding leads to a better reproducibility with respect to manual crushing. Similar results were obtained also with EWV measurements. Mechanical grinding was then chosen as sample pre-treatment technique.

\subsection{Temperature}

The sample heating temperature plays a very important role in the amount of water determined in the samples. The measurements with the three techniques were carried out at $110{ }^{\circ} \mathrm{C}$ for comparability with the usual temperatures set for the LoD detections.

Additional measurements were performed by $\mathrm{cKF}$ and EWV at higher temperatures reaching a maximum value of $220{ }^{\circ} \mathrm{C}$, recommended for the reference material used for the instrument calibrations. It was observed that the measured moisture content increased with at higher temperatures. On one side, these results could suggest that the temperature of $110{ }^{\circ} \mathrm{C}$ is not enough to a 
quantitative extraction of the water present in the pellet samples. On the other hand, increasing too much the temperature might lead to degradation processes of the pellet constituents (like lignin, cellulose) thus generating additional water.

\subsection{Comparison of the results}

Figure 2 reports the results obtained on ground wood pellets with both $\mathrm{cKF}$ and EWV and also the value given by $\mathrm{TG}$, used as a confirmation technique. The measurements were carried out using a sample heating temperature of $110{ }^{\circ} \mathrm{C}$.

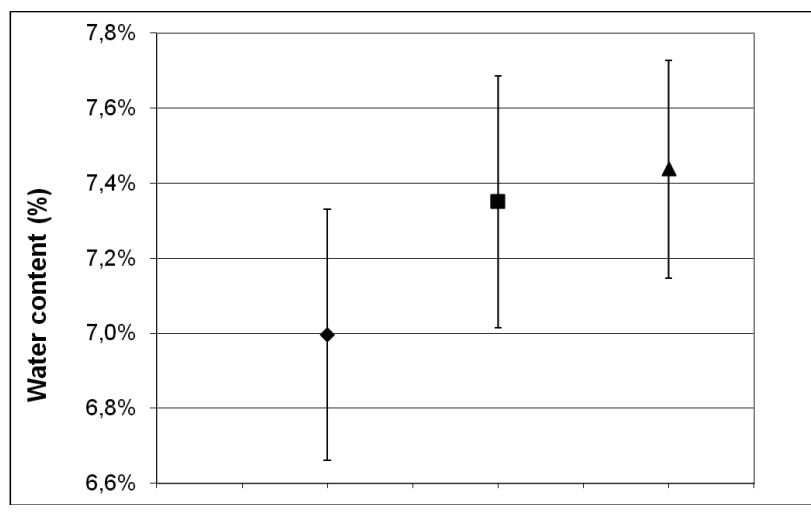

Figure 2. Comparison among TG (४), $\operatorname{cKF}(\boldsymbol{\bullet})$ and $\operatorname{EWV}(\boldsymbol{\Delta})$ results for wood pellets at $110{ }^{\circ} \mathrm{C}$. The expanded uncertainties are the standard deviations of repeated measurements multiplied by $k=2$

The results show good agreement, particularly for $\mathrm{cKF}$ and EWV, both in terms of measured value and uncertainty. The TG determination gave a lower water content compared with the two coulometric techniques but in agreement within the stated uncertainties. During the TG measurement, the sample remains in contact with the external environment and this might result in loss of water from the sample itself.

\section{Conclusions}

The present paper describes the work carried out at INRiM to set up metrologically-sound procedures for the determination of water content in samples of wood pellets. Two electrochemical methods, namely coulometric Karl Fischer (cKF) titration and Evolved Water Vapour analysis (EWV) were used and the thermogravimetry (TG), which is included among the LoD techniques, was considered as an additional confirmation technique. The coulometric methods that are based on chemical reactions selective to water, can be considered as promising techniques for moisture measurements in solid materials.

A particular attention was paid in assuring metrological traceability to the results by using calibrated mass standards for the weighing procedures and certified reference materials to calibrate the analysers.

The obtained results showed a good agreement among the above techniques, but TG gave lower water content with respect to the coulometric techniques. Sample homogeneity and drying temperature were found to be the most important influence quantities in the entire moisture determination process.

Additional work is foreseen for determining the most suitable sample heating temperature to allow a quantitative extraction of water without causing degradation phenomena in the samples.

\section{Acknowledgements}

The present work was carried out within the European Joint Research Project "SIB64 METefnet - Metrology for Moisture in Materials". The project is funded by European Metrology Research Programme (EMRP), implemented by European Association of National Metrology Institutes (EURAMET).

\section{References}

1. V. Francescato, E. Antonini, L. Zuccoli Bergomi, Wood fuels Handbook (AIEL - Italian Agriforestry Energy Association, 2008)

2. D. C. Hinz, J. Pharm. Biomed. Anal, 43, 2, 779-783 (2007)

3. http//www.metef.net/ 